\title{
Alexander Baumgarten on the Principle OF SUFFICIENT REASON
}

\author{
Courtney D. Fugate \\ (American University of Beirut/ Emory University)
}

\section{Introduction}

There are several reasons to be interested in what Alexander Baumgarten has to say about the Principle of Sufficient Reason (PSR). Historically speaking, his treatment of the PSR served nearly all later German thinkers as the locus classicus for both its definition and its proof. When Kant, for instance, discusses the principle in his Nova dilucidatio, he refers only generally to Leibniz and Wolff, but cites specifically the proof as it is "expounded more distinctly by the penetrating Baumgarten" (AA 1:397). We also know that Baumgarten's textbook, and consequently also his treatment of the PSR, held a similarly authoritative place in the thought of figures like Moses Mendelssohn, Thomas Abbt, Solomon Maimon and Johann Gottfried Herder.

Philosophically speaking, it might equally prove interesting to look more deeply into Baumgarten's treatment of this principle, since his defense of it was evidently based upon a critical examination not only of the arguments in its favor, but also of the strongest known objections to it. From several sources, it is clear that Baumgarten was educated by those who opposed both Leibniz and Wolff and rejected the PSR, and that initially he also rejected the principle (Baumgarten 2013, p. 77). In his Philosophical Letters, Baumgarten recalls in particular how during his youth the philosophies of Leibniz and Wolff were widely regarded as a form of crypto-Spinozism, and how he experienced both social and familial pressures to distance himself from it (Baumgarten 1741, p. 2-3). Yet he goes on to explain that after scrupulously researching the former controversy between Wolff and the Pietists - at the center of which was, naturally, the PSR - he was led not only to accept the principle, but to accept that it is

Philosophica, 44, Lisboa, 2014, pp. 127-147. 
"coextensive not only with everything that exists, but indeed also with everything that is possible, without exception" (Baumgarten 2013, p. 78). It is thus clear that Baumgarten's understanding of the principle was forged in a context that was not only hostile to the PSR, but was also significantly more sophisticated in its opposition than was the case when Leibniz first formally introduced the PSR, or when Wolff later tried to provide PSR with a strict proof. All of this strongly suggests that we should resist the temptation to ascribe Baumgarten's maintenance of the PSR to a blind adherence to the rationalist tradition and that we should expect his treatment of it to have a rather solid philosophical core.

In the following I will defend the PSR, taking Baumgarten as my guide. My primary aim is not to vindicate the principle itself, but rather to explore the kinds of resources I suspect Baumgarten originally thought sufficient to justify the PSR against its early opponents. Even if this does not lead us to accept the PSR, it may at least lead us to a deeper understanding of what, according to Baumgarten, the principle really assumes and intends. Due to limitations of space, I will consider here only objections to Baumgarten's proof that do not draw upon Kant's Critical philosophy. Naturally, if it turns out that Baumgarten's proof cannot be easily refuted by these pre-Critical arguments - and it is widely assumed that it can - then there will be all the more reason to consider Kant's critical response to the PSR in more detail at a later time. ${ }^{1}$

\section{Baumgarten's Proof of the PSR}

Baumgarten's proof of the principle of reason or ground (principium rationis) is as follows:

Everything possible either has a ground or does not. If it has a ground, something is its ground. If it does not have one, nothing is its ground. Therefore, the ground of every possible thing is either something or nothing. If nothing were the ground of some possible thing, it would be knowable from nothing why that thing is, and hence the nothing would be something. Hence something possible would be impossible, which is absurd. Therefore, something is the ground of every possible thing, which is to say everything possible is a consequence, which is to say nothing is without ground, or when something is posited, something is posited as its ground. (Baumgarten 2013, $\$ 20)^{2}$

\footnotetext{
${ }^{1}$ Longuenesse 2005 proposes to do just this, although I disagree with many of the details of her argument, particularly as it concerns Kant's Nova dilucidatio. See below.

${ }^{2}$ One should note that contrary to Gawlick and Kreimendahl's suggestion, the
} 
This leads trivially to the PSR, since it means: "Each and every thing in every possible thing has a ground; hence, every possible thing has a sufficient ground" (Baumgarten 2013, §22).

The proof clearly rests on two key points. The first is found in the third sentence: "If it does not have one [i.e. a ground], then nothing is its ground." Here Baumgarten makes a controversial move from the denial of a positive predicate in "does not have a ground" ("non habet [ratio]") to the affirmation of a positive predicate regarding the subject "nothing" in "nothing is its ground" ("nihil est eius ratio"). The second key point is the assertion that, since a ground is something from which one can know why something is, to say "nothing is its ground" is to say that it is "knowable from nothing why that thing is," which implies we can represent "nothing." But "nothing" is precisely what cannot be represented, the impossible or contradictory, whereas what can be represented is by definition "something," the possible, the non-contradictory (Baumgarten 2013, §7, 9). So we are covertly identifying nothing with something or the impossible with the possible, which is absurd because it is contradictory.

Before considering objections to this argument, it is important to see how its second key point distinguishes Baumgarten's proof in a subtle but important way from that of his famous predecessor, Christian Wolff. Wolff provides at least two proofs of the PSR, or at least two formulations of a proof, a shorter one in his German Metaphysics and a much longer one in his Latin Ontology. I will focus here only on the latter, more explicit treatment. ${ }^{3}$ The proximal argument runs as follows:

The principle of sufficient ground is proven. Nothing is without a sufficient ground why it is rather than is not; i.e. if something is posited as being, there will also be posited something from which it is understood why this thing is rather than is not. Indeed, either nothing is without sufficient ground why it is rather than is not, or something can be without sufficient ground why it is rather than is not. We suppose that A is without sufficient ground as to why it is rather than is not. Therefore, nothing will be posited from which it is understood why A is. Hence, it will be admitted that A is, because nothing has been assumed: Since this is absurd, nothing is without sufficient

abbreviation "q.a." clearly means "quod absurdum est." For a full discussion of this point, see Baumgarten 2013, p. 58-59.

${ }^{3}$ In Wolff 2005, p. XXVII, Dirk Effertz suggests that the two are distinct in their characterizations of what kind of ground nothing is to be, i.e. whether it is an efficient or material cause. It is unclear to me if this is really a significant difference. 
ground, or, if something is posited as being, it is also admitted that something is from which it is understood why it is. (Wolff 2005, §70)

On the surface, Wolff's proof-strategy in this paragraph is fairly traditional. The nervus probandi lies in the statement that it is absurd to claim that something is because of nothing. This seems to recall the famous principle "ex nihilo nihil fit," which has been adduced to support principles resembling the PSR since at least Parmenides. Indeed, this is the kind of proof usually adduced by Wolff's own followers. ${ }^{4}$ In this same respect, it would seem to differ markedly from Baumgarten's proof, which locates an absurdity, not immediately in the claim that something can come from nothing, but rather in the assertion of the contradiction that nothing is something.

But if we delve a bit deeper into the preceding paragraphs in the Latin Ontology, we will find such suggestions unfounded. Wolff does not simply adduce the principle "ex nihilo nihil fit" as if it were an axiom, but rather attempts to prove it. In a manner that clearly anticipates Baumgarten's later formulation, this proof lies in a detailed account of representation and the conditions of meaningful speech (i.e. an account of "termini inanes"). So in the lead-up to the proof, Wolff explains that nothing is "that to which no concept corresponds" (\$57), whereas something is "that to which a concept corresponds" (\$59); that "nothing" and "something" are thus contradictory opposites ( $\$ 60)$; that an empty term is one to which no concept corresponds, and thus which denotes nothing, but yet has a deceptive concept of something attributed to it (§63); that an empty expression cannot occupy the place of a ground, because a ground is that from which one is to understand why something

\footnotetext{
${ }^{4}$ See e.g., Reinbeck 1740, p. 13: "Whoever denies this proposition, and therefore would maintain that something can also indeed be without a sufficient ground, would have to admit that something could produce itself from nothing or that a nothing could produce something. For, if something can be actually be present, that yet has no ground at all, neither within it nor outside of it, as to why it is present; then there is nothing there which explains why it is present. Now, however, it is nevertheless present; thus it would have come to be from nothing. Here, however, an obvious contradiction reveals itself: A nothing is, and indeed has produced something. If one wished to say that it has brought forth itself; then the contradiction is again obvious. For, had it produced itself, then it would already have to be before it would have come to be. Now, however, it is an obvious contradiction, to already be before one comes to be. For this reason it remains an eternal truth: Everything must have its sufficient ground, why it is; why it is so, and not otherwise. Accordingly, whoever does not wish to admit this should not be opposed, lest one further waste another word with them; rather such a person would deserve the most distinguished position in a madhouse, just as would a person who believed that something could be black and white at the same time."
} 
is, and through an empty expression one understands nothing $(\$ 65,66)$; that no predicate can be ascribed to "nothing," because then it would have a concept and be something (\$67); and finally that it is absurd to claim that something can be posited when nothing is posited, since by this nothing would either have to become something (which is contrary to $\S 60,61$ ) or nothing would have to bring about something (in which case it would have "being the cause of something" as a predicate, contrary to $\S 67){ }^{5}$

Even from this schematic summary, it is clear that Wolff's proof turns on the basic idea that by the term "nothing" one genuinely has no thought, only a term without a thought. It is a consequence of this idea that one who would maintain the falsity of the PSR, and thus that "something is without a reason," is really using an empty expression, i.e. in making this statement they are saying nothing, but doing so under a deceptive concept which makes them believe they are referring to something. The deceptive concept in this case, depending on what they intend by their words, is either the thinking of nothing as something simply, or the ascription of a predicate to nothing, which also means to think it as something.

As we saw above, Baumgarten's proof also does not turn on the simple absurdity of regarding nothing as the cause of something, but more precisely on the contradiction of identifying nothing with something, which he argues is logically equivalent to the denial of the PSR. The only real but still important difference, then, between this and Wolff's proof is that Baumgarten has managed to brilliantly pare down the argument to its most essential components so that the intimate connection between the PSR and the principle of contradiction something largely obscured in Wolff's treatment - is almost immediately evident.

\section{Four Objections to Baumgarten's Proof}

Equivocation. The first of the key points of Baumgarten's proof mentioned above has long been regarded by commentators as a simple logical fallacy of equivocation. Baumgarten would seem to equivocate precisely by allowing "does not have a ground" to mean "nothing is its

${ }^{5}$ Cf. Baumeister's formulation: "If, namely, anything whatsoever were without a sufficient ground, then the nothing (" $\tau o ́$ nihilum") would produce something, and to this extent the nothing would exist (because otherwise it would not be possible for something to be produced) and not exist (because otherwise it would not be nothing), which indeed cannot be by virtue of the principle of contradiction." See Baumeister 1747, p. 144; cf. Baumeister 1754, p. 31-32. 
ground." This would be fine, so the objection goes, if "nothing" were here still taken to mean "no thing." But in the fifth sentence Baumgarten takes "nothing is its ground" to imply that nothing really is represented as a ground and thus as something, thereby equivocating. Kant makes this objection several times, first in the Nova dilucidatio (AA 1:397-398), but most clearly in his handwritten note 4009 , which reads in part:

In this demonstration 1. the word "nothing" in a logical sense (which means so much as the universal negation in a judgment and affects the copula of a universal judgment) is confused with the "nothing," namely the removal of the contents [der Sachen]. E.g. no thing has a ground, nothing has a ground, and: the nothing is the ground of some things.

Later in the Mrongovius lecture notes, he states similarly:

The author has proven it [i.e. the PSR], but rather remarkably, namely: if a thing were to have no ground, then its ground would be nothing. Then nothing would be the ground of something, but that is a contradiction. Here he has confused the logical and metaphysical nothing, which is hardly pardonable. ... The mistake is that nothing is meant one time as negation, another time as a concept. (AA 29:815816)

In making this objection, Kant is following a line of thought stated earlier by Christian Crusius. Put simply, the claim is that saying "a thing has no sufficient ground" is equivalent to saying "nothing is its ground," only if we remember that in the second locution "nothing" is just another way of expressing the negative verb form in "does not have a ground" ("non habet"). However, when we take the second locution to mean "the nothing" is its ground, rather than simply that "no thing" is its ground, hypostatizing "no thing" into "nothing" as it were, we are equivocating. As Crusius explains, one who says that a thing has no ground, has simply no intention of asserting in addition that "the nothing" is its ground (cf. Crusius 1987, p. 178ff.). To use Kant's terms, we must recognize that in the former case "nothing" paraphrases a logical negation, whereas in the latter it designates the metaphysical concept of nothing, which consists in an actual denial of any thinkable content.

Nevertheless, it seems much more reasonable to suppose that, rather than equivocating, Baumgarten is in fact making the substantive philosophical claim that to think of something as the case but as having no ground can mean nothing other than to represent its ground as nothing, i.e. that the only positive meaning there can be of the logical negation of a ground is the affirmation of the metaphysical nothing as a 
ground, which would be contradictory. In other words, perhaps there is a logical contradiction buried in the assertion that we can truly think or represent something as the case and at the same time represent it as really having no ground for its being the case. For, according to Baumgarten's account, the locution "having no ground" must have content, if it is to be meaningful, i.e. it must correspond to some positive thought, a representation. But the only positive thought it can correspond to, when properly understood, is perhaps that the "nothing" - in the metaphysical sense - is the ground. And here again we are either saying nothing at all using empty terms - and so the PSR is not denied, or else we must be thinking something positive by "nothing," i.e. a something, thus not truly nothing, although we are still using the word. On this account, it is really Baumgarten's supposed critics, Kant included, who are caught in an equivocation, and worse still, this equivocation masks a contradiction in their own use of "nothing." His point would then be just this: Try to represent something as having no ground and you thereby necessarily think of nothing as something, which is contradictory. The true import of the principle of sufficient reason would then actually consists in our inability to conceive of something as ungrounded without in the same thought unwittingly asserting that nothing is something. Baumgarten would thereby deny that there is or can be a distinction between logical negation of something's possessing a ground and the representation of nothing as its ground. This would then be part of the very meaning of the PSR itself.

Another way to articulate the same point is to focus on Baumgarten's definition of ground, and how this informs the second key part of the proof outlined above. Ground is "that from which it is knowable why something is" (Baumgarten 2013, p. 102). Thus Baumgarten's point would seem to be that if you maintain it is possible for something to be the case and yet for it also to not have a ground, you are maintaining that you can know or represent that something is the case on the basis of nothing, i.e. on the basis of no other representation. But one cannot know something or have a reason for representing it one way rather than another based upon nothing whatsoever. So whoever maintains this is confused; in truth, they must either admit that they know or represent nothing, or that under "nothing" they at least think "something." This would be like someone saying that they can understand how two boards can actually be separated and yet be separated by nothing: if their words are to make any sense, then by "nothing" they must really mean empty space, not nothing in the genuine or metaphysical sense. If they are consistent, they should therefore say that they cannot understand how two things can be separated by nothing, 
because to be separated by nothing is not to be separated (notice the equivalence of the metaphysical and logical sense of "nothing" here). Baumgarten would claim similarly that his opponents should not say that they can represent or know something on the basis of nothing, but rather that they cannot represent anything this way at all; which means, they should say that they can only represent something as grounded in something else, and thus admit the PSR. The key point is that the representation of something as having no ground must either be the representation of the thing itself only as neither being the case nor not being the case, which is then not really the representation of its being the case and having no ground, or it must be the representation of it as grounded in something, which we mistakenly call by the name "nothing." In either case, it is impossible to consistently represent a thing as having no ground. That Baumgarten believes his opponents to be caught in just such an equivocation is strongly suggested by his claim that his opponents, "negating the universal principle of ground, will be forced to call [the ground of something possible] nothing due to [their] premises" (Baumgarten 2013, p. 80). That is, they are thus "forced to call" something by the name "nothing" due to their denial of the PSR.

On this basis, it is easy to understand why someone like Crusius would find such an argument unconvincing. As Kant himself notes in the Nova dilucidatio, Crusius thinks that the mere experience of certain kinds of events or actions is sufficient to provide a ground for our representation of them as being the case, without there needing to be any antecedent determining conditions in the thing itself (AA 1:397). This immediately explains why Crusius thinks the move from "something has no ground" to the statement "the nothing is its ground," to be illegitimate. If mere empirical experience is sufficient ground for our representing something to be the case, then it seems obvious that the latter does not necessary require the actual rational representation of the thing as having a ground. Yet this very realization makes it all the more mysterious as to why the young Kant would so readily adopt Crusius' line of argument against Baumgarten's proof. For Kant openly rejects the view that an event or action can exist without sufficient ground as well as the view that we can represent an event or action as being the case, i.e. as being true, without representing a ground for this truth.

To better understand this we must consider Kant's own proof of several principles related to the PSR in the Nova dilucidatio. His first innovation is to distinguish two related forms of the PSR. The first is the principle that "nothing is true without a determining ground" (AA 1:393, emphasis added); the second, that "nothing which exists contingently can be without a ground which determines its existence antecedently" (AA 
1:396, emphasis added). Kant thinks the first principle follows on pain of contradiction from the very definition of representing a thing as true. In short, to represent a proposition such as " $\mathrm{S}$ is $\mathrm{P}$ " as true means to represent $\mathrm{S}$ as determined by the predicate $\mathrm{P}$ and thus as not determined by the predicate $\sim \mathrm{P}$. But only "from the concept of a ground is it possible to understand which of the opposed predicates is to be ascribed to the subject and which is to be denied," and so without the concept of a ground there can be no truth. As Kant notes, this proof does not distinguish between what he calls consequently and antecedently determining grounds of truth - i.e., genuine grounds of holding something to be true that are coordinated with, but do not bring into being the truth in question, and those that do bring it into being as well although he does admit that one can conclude from a closer inspection of this proof that there must always be an antecedently determining ground; for otherwise, there would be no ground of the existence of a given truth (AA 1:394). The second principle is proven as follows: Suppose a contingent thing were to exist without a ground for its existence. Then it would be determined to exist by itself, with no further ground. That is to say, its non-existence would be excluded by itself, with no further ground. Its existence would hence be absolutely necessary. This contradicts the supposition. Consequently, it cannot be true that a contingent thing can exist without a ground, i.e. the existence of all contingent things requires a determining ground. ${ }^{6}$

${ }^{6}$ Longuenesse 2005 interprets what I refer to as Kant's three forms of the PSR very differently. She seems to think that the principle of truth is Kant's general PSR at this time and that the principles of possibility and existence are its consequences, whereas I take the three to be coordinate principles and their respective proofs to be independent. Her basis for this belief appears to be Kant's statement that the principle of truth also leads in some way to the principle of antecedently determining ground. Firstly, however, Kant claims only after his proof that one can also somehow see that there must always be an antecedent ground of all true propositions, not of all things in general. Secondly, his suggestion is that actually this rests on the fact that there must be something to bring a truth into being, i.e. there must be a ground of the existence of any truth, which can only be an antecedently determining ground. I take this only as Kant's proleptic indication that the principle of determining ground with respect to truth can be seen to lead to a principle of antecedently determining ground with respect to truth when combined with the principle of existence adduced later. Furthermore, in order for Longuenesse's reconstruction of the principle of existence to succeed, Kant must have thought at the time that existence is complete determination with respect to predicates, for only in this case could a principle of the determining ground with regard to the truth of propositions lead logically to the conclusion that there must be a ground of existence. But by this time Kant has clearly reached the view that existence itself is not equivalent with complete determination. By contrast, my 
In addition to these two limited forms of the PSR, there is yet a third significant variation at work in Kant's proof of God's existence, which occupies him in the single section between those containing the two proofs above. The principle is this: "nothing can be conceived as possible unless whatever is real in every possible thing exists" prior to it (AA 1:395). Unlike the former two, which concern grounds of truth and grounds of existence respectively, this principle concerns specifically the grounds of possibility. It states that all possibility requires an absolutely necessarily existing ground. Kant supports this principle by arguing that the representation of possibility arises from the comparison of two or more things that are already given to be thought (AA 1:395). Thus were nothing given to thought at all, nothing could be compared, and hence possibility would vanish. So if there were no such thinkable content to ground the thought of possibility, "no thing at all would be possible" (AA 1:395). This principle is later adduced for the same purpose in The Only Possible Argument, where Kant makes it clear that its proof should run something like this: "to say that there is a possibility and yet nothing actual at all is self-contradictory. For if nothing exists, then nothing which could be thought is given either, and we contradict ourselves if we still wish to say that something is possible." As he goes on to explain: "Accordingly, the assertion 'There is nothing that exists' means the same as the assertion 'There is nothing whatever.' And it is obviously selfcontradictory to add, in spite of this, 'Something is possible" (AA 2:78). ${ }^{7}$ In short, if we assume some possibility, then it is contradictory to also maintain that there is nothing. For the denial that there is anything posited by itself (existing), is at the same time the denial that there is anything at all, even relatively. In other words, even relative positing (possibility) presupposes something posited simply or by itself (thus as existing). Kant notes that this principle allows for two possibilities, either that the ground of possibility is found in the existence of the same thing in which the possibility is found (which holds for God alone), or else it lies in the existence of some other thing (which holds for all things other than God).

Having examined Kant's three principles of reason or ground in the Nova dilucidatio, it is now possible to evaluate their relation to Baumgarten's proof of the general PSR and to explain Kant's

reading of Kant's proof of the principle of the determining ground of existence in no way rests on the proof of the principle of truth. It rests only on the contradiction that would arise from holding that something contingent might exist without a ground, since to exist without a ground is, on Kant's analysis, the same as existing with absolute necessity. See Longuenesse 2005, esp. p. 124-128.

${ }^{7}$ These translations have been modified from the Cambridge Translation to better reflect the original. 
maintenance of Crusius' main argument against it. Firstly, it should be noted that Kant's principle of ground regarding truths would seem to be a simple instance of Baumgarten's principle of ground with respect to all possible things. Indeed, Kant simply applies the strategy of Baumgarten's proof regarding the representation of all possible things to the representation of all true propositions. For just as Baumgarten argues that it would be contradictory to state that we represent something (by which he naturally means genuinely or truly represent), without representing a ground of this, Kant argues that it would be contradictory to represent the truth "S is P" without also representing that this truth has a ground. One could thus easily reformulate Kant's proof, without loss, in the same way as Baumgarten's: If there were no ground of the truth " $\mathrm{S}$ is $\mathrm{P}$," then nothing would be its ground. So nothing would be the reason for determining $\mathrm{S}$ by $\mathrm{P}$ rather than by $\sim \mathrm{P}$. But nothing cannot be the ground of this or any determination (cf. Wolff 2005, p. 150: "Posito nihilo non poni aliquid"), because then it would have to be something, which would result in a contradiction. The difference between the two is only superficial. Whereas Kant prefers the straightforward formulation in terms of logical negation, and derives a contradiction from the assertion that something whose concept logically implies a ground has no ground, Baumgarten would prefer to formulate it in terms of the deceptive concept of a nothing thought as a ground. Kant's proof is thus clearer, but Baumgarten's better reflects the kind of deception at work when one believes oneself able to represent a thing, in this case, as true, without a ground.

With his principle of the ground of existence, however, Kant makes an important revision of the traditional proof of the PSR. As Kant explains further in the Only Possible Argument, being as such is equivalent with positing. But positing can be either relative or absolute, that is, it can either be of something in relation to something else or of a thing as such and in itself (non-relatively). The former is relative positing, whereas the latter is nothing but the concept of existence (AA 2:73-74). Now, since existence is non-relative positing, there is nothing in the concept of the existence of a thing as such that requires an external ground. So the apagogic proof cited above is able to arrive at a contradiction only from the assumption that a contingently existing, i.e. relatively existing, thing should be without a ground. As it states, if a thing exists and yet does so without a ground, i.e. non-relatively, then its existence is absolutely necessary; its opposite is excluded by itself. But this contradicts the assumption of a thing whose existence is contingent. Again, the proof can easily be put into a form similar to Baumgarten's more general argument: Represent a thing as existing contingently and as 
having no ground; then nothing (which is just the deceptive concept covertly containing Kant's logical contradiction "a contingent thing having no ground, which is thus absolutely necessary") must be the ground of its existence. But if this is to remain the representation of a contingent thing, nothing must be thought here covertly as being something, since nothing truly cannot serve as a ground. Hence, when we represent a thing as existing contingently and as having no ground, we are essentially representing nothing as something, which is contradictory. So the proof again can be taken as a limited application of Baumgarten's more general proof of the PSR. The only real difference is what Kant's proof leaves out, namely, any attempt to prove that existence as such requires a determining ground.

All of this comes to a focus in the third principle discussed above, the PSR as it concerns possibility. It is crucial to sharply distinguish this principle from Baumgarten's, which asserts that everything possible must have a ground. Kant's, by contrast, merely asserts that every possibility must have a ground. Still, observing this restriction, one can easily reformulate Kant's proof in a way that even more closely mirrors Baumgarten's proof of the PSR, but applied specifically to the case of possibilities: Suppose something is possible, but that there is nothing to ground this possibility. Then nothing must be the ground of this possibility. But if we are to continue to mean by "possibility" what we meant before, namely, the positing of a thing relative to some content given to thought absolutely, i.e. something, then nothing must be represented as something, which would be contradictory. All that Kant really adds to this proof is an analysis of existence as non-relative or absolute positing, which allows him to conclude that this ground must be something existing, because it must be given to thought, and thus posited, as the first and thus non-relational ground of possibility.

Hence, by examining all three of Kant's principles of ground it becomes clear that he replicates nearly everything that was contained in Baumgarten's proof of the PSR - that all truths, possibilities and finite or contingently existing things must possess a determining or sufficient ground of their being so and not otherwise - and that he does so using basically the same kind of argument, a reductio ad absurdum. All of Kant's subtle distinctions seem, however, to be motivated by the desire to allow one sole exception to the PSR, namely the absolutely necessary existence of God. That God's existence is absolutely necessary, of course, must have a determining ground of its truth, as is demanded by Kant's first principle, which ground is actually adduced in the third principle concerning the grounds of possibility. Yet the existence of God itself does not, he believes, require an antecedently determining ground, since 
it is not contingent. Thus by the clever moves of restricting the principle of existence to contingent things, and then basing the proof of God's existence on the principle of possibility and allowing that existence need not always precede possibility, it would seem that Kant is able to maintain a proof of God's absolutely necessary existence while still claiming that every cause must precede its effect, and so that God cannot be cause of himself.

If this analysis is accurate, then Kant evidently borrows Crusius' line of attack on the proof of the PSR, not simply because there is an equivocation underlying the move from "something has no ground" to "nothing is its ground," but because this move is only valid, in his view, in the specific cases where the something in question is either a true proposition, the representation of a contingently existing being, or the representation of some possibility. It is built into the very concepts of such things that they must have a ground, and so it is indeed true that their having no ground is equivalent with asserting that the metaphysical nothing is their ground, which is then equivalent with asserting a contradiction. It is only in the case of existence as such, and only to the extent that Kant conceives of this as consisting in nothing other than absolute or non-relational positing, that "existence has no ground" cannot be converted to yield "nothing is its ground." But, of course, this is only an equivocation if one already accepts Kant's substantive analysis of being as positing and of existence as absolute positing, which Baumgarten evidently does not.

Begging the Question. A second pre-Critical objection worth discussing is that Baumgarten somehow presupposes what he intends to prove when he equates a thing's "not having a ground" with the claim "nothing is its ground." Does this not simply reassert that the thing must have a ground, in this case, nothing? To see why this objection fails, we must think a bit about what "proof" means in a case like this. Like Wolff, Baumgarten presumes to prove the PSR from the principle of contradiction alone. If we look at the proof stated earlier, we can see this in the fact that "something" is defined as what is not contradictory, "nothing" as what is contradictory, while the proof itself is apagogic - it claims to prove the PSR from the fact that its denial is contradictory. So all components and principles cited in the proof lead back to the principle of contradiction and the definition of ground. There is thus no question that the proof is intended to be purely logical. And surely Baumgarten was a good enough logician to realize that you cannot get out of a logical proof more than is already present, although implicitly, in the premises.

In this sense, then, Baumgarten is evidently presupposing the PSR in his proof; for if the proof is valid, the PSR must be contained within or 
equivalent to the principle of contradiction and the definition of ground, its sole presuppositions. But to think this constitutes an objection is to misunderstand the nature of logical proof. We should understand the proof here therefore not as adducing something new, but rather as unfolding for us another aspect of the truth of the principle of contradiction in its application to the definition of ground, both of which are recognized as being indemonstrable. In this respect, the principle of contradiction and the PSR can well be regarded as equivalent, not subordinated truths. And if the premises are admitted to be indemonstrable, there is equal justification for regarding the PSR as such. If we nevertheless offer a proof of it, then, this is only to help others see that it really is already contained in something they accept as indemonstrable. In any case, in no way should the intrinsic truth of the PSR be thought to rest on the proof itself; the proof only makes its truth evident. It seems to be in this vein, that when pressed by his critics, Baumgarten responds with indifference as to whether one regards the PSR as an indemonstrable or as a demonstrable proposition. ${ }^{8}$ As he writes,

You demand a proof, or rather a demonstration? Which one? What if I counted the principle of ground among the indemonstrable propositions, i.e. those propositions of which you would become completely certain as soon as the mere terms are understood? ... What if I said that "every possible thing has a ground" is an identical proposition? If only these sorts of claims were never made about things that are less evident! But let it be a demonstrative proposition... (Baumgarten 2013, p. 78)

Still, the objection can be refined by saying the charge is not that Baumgarten has presupposed the PSR, but that he illegitimately introduces the PSR at some point in the proof before he properly shows how it flows logically from the principle of contradiction. But Baumgarten has anticipated this refinement as well, and challenges his critic to find a place where he introduces the principle prior to the final line of the proof. And in this he seems to be correct, although I will not belabor the point here.

Refutation by Comparison. A third important objection made to Baumgarten's proof is that one can prove any number of absurd conclusions in a similar way. This objection is voiced by Kant, but was

\footnotetext{
${ }^{8}$ The importance of this passage was brought home to me by comments made by Brandon Look in his presentation "Baumgarten's Rationalism."
} 
apparently raised early enough by others for Baumgarten to respond to it himself in the third Preface to the Metaphysics. There he notes that this is a traditional logical method of refutation called comparison. For example, one might argue that if Baumgarten's proof of the PSR is valid, then so is this:

Every possible thing has extension. Proof: Every possible thing either has extension or not. If it has extension, its extension is something. If it does not have extension, its extension is nothing. Therefore, the extension of every possible thing would either be nothing or something. If the extension of something possible were nothing, nothing would be something. (Baumgarten 2013, p. 79) ${ }^{9}$

Baumgarten admits every step of the proof, except the last. As he goes on to explain, although the structure is parallel, the final line of this supposed proof, unlike the final line of his own proof, has not been properly justified. Recall that Baumgarten's own line was this: "If nothing were the ground of some possible thing, it would be knowable from nothing why that thing is, and hence the nothing would be something." Here the move from the claim that "nothing is the ground" to the fact it must be representable, and thus something, is explained by the notion of a ground as "that from which it is knowable why something is." By comparison, there is nothing in the supposed parallel to explain why if the extension of something is nothing, it must be represented as something. As Baumgarten writes:

If I were to posit the extension of some possible thing to be nothing, impossible, not representable, i.e. if I were to posit the antecedent to your last hypothetical proposition, I nevertheless do not see why I am compelled to posit the consequent, which I concede is absurd, until you have proven with equal certitude that the extension of some possible thing ought to be impossible and nevertheless likewise representable, just as I proved that the ground of some possible thing..., precisely because it is called the ground, must be admitted to be likewise understandable, representable, and hence to be something and possible. (Baumgarten 2013, p. 80)

Baumgarten's point clearly is that while the structure is parallel, the content, which is essential to the validity of the proof, is quite different. His own proof rests on the essential connection of the concepts of ground, representation or understanding and something, a connection that simply

\footnotetext{
${ }^{9}$ I have condensed Baumgarten's text by omitting parts inessential to my present point.
} 
does not exist between the concepts of "not being extended" and something. One way to see this more clearly, is to note that "not being extended" actually does not logically imply "nothing is its extension," because the negation of being extended is not only consistent with but can also be the logical consequence of its having many other positive predicates. So "not being extended" can, for instance, be a logical consequence of "being simple." The only negation then that would logically imply that nothing belongs to a thing as a predicate, would have to be "has no predicates." In this case, Baumgarten would argue, "nothing" would have to be its predicate (for with no predicate we would not be thinking a thing at all). But since to be a predicate is to be something, nothing would be something, which is absurd. So everything must have some positive predicate. This surely is an argument Baumgarten would defend (cf. Baumgarten 2013, §53).

Now, remarkably, Kant employs the same method of comparison, indeed suggesting it is the best way to refute Baumgarten's proof. His example, however, is somewhat different from the one discussed by Baumgarten himself, and is again evidently inspired by Crusius (cf. Crusius 1987, p. 179). As Kant writes:

According to this method of inference I shall venture to prove that even the first human being was begotten by a father. For suppose that he was not begotten. Then it would be nothing which would have begotten him. He would, therefore, have been begotten by nothing. But since this is contradictory, it must be admitted that he was begotten by someone. It is not difficult to escape the sophistry of the argument. (AA 1:398)

Sophistry indeed. But Baumgarten's or Kant's? First, it should be noted that in one key respect Kant has done a very poor job of constructing a parallel argument. He entirely omits the reference to understanding or representation, which, as we have seen, is absolutely essential to Baumgarten's proof. On the positive side, with the help of Crusius, Kant has indeed slightly improved on the attempted refutation by comparison that concerned extension by introducing instead the notion of "begetting," which is in a sense a kind of grounding, making the content somewhat closer to the PSR.

However, here Kant's own sophistry reveals itself: He aims to prove the patently absurd proposition that the first human being was begotten by a father. Then he says: "For suppose that he was not begotten. Then it would be nothing which would have begotten him." But this certainly does not follow, because being "begotten by a father" is not the only way that someone can possibly come to be, and as in the parallel case of extension, 
it can even be the logical consequence of another way of coming to be, such as Adam's immediate creation by God. It simply does not follow, even on Baumgarten's principles, that if one is not begotten by another human being, then nothing begot them. And so it does not follow that one was begotten by nothing, and the whole proof unravels. What Baumgarten would presumably admit is that if we were to maintain that there is no ground or reason at all for their coming into being, then we would be committed to the claim that no thing was the ground of their coming into being, that nothing caused them to be. So while Kant's argument cannot prove that the first human being was begotten by a father, if adjusted it can prove that the coming into being of the first human being must have had a ground. But that is just what Baumgarten's proof maintains. Kant thus commits the same mistake as the previous attempt at refutation by comparison; for just as the concept of "not having extension" does not stand in any demonstrable relation to understanding or representation, and thereby to something, neither does "not being begotten by a father." What does stand in such a relation, in Baumgarten's view, is the concept of a ground or reason. Attempted refutations by comparison thus fail simply because not just any concept stands in the kind of essential relation with being and representation as does that of reason or ground.

Patent Absurdity. A fourth objection, again made by Kant, is startlingly obvious, but deep in its implications. The principle of sufficient reason means, as Baumgarten explicitly notes, that "everything possible is a consequence." As Kant's Metaphysic lecture $\mathrm{L}_{2}$ reads:

In order to comprehend the falsity of this universal principle, one need only put it into other words: whatever is, is a consequence. Here one sees at once that it will not do. So all things are consequences? From what then do they follow? The impossibility of this principle thus strikes the eyes at once. (AA 28:551)

If the absurdity of this strikes the eyes at once, then why didn't it strike Baumgarten, who explicitly formulates the principle in this way? The answer, it seems, is that Baumgarten himself did not regard it as absurd for a very simple and powerful reason: the need to think of things as grounded in something really prior, and thus as absolutely subordinated, is a limitation attaching only to finite human knowledge. In fact, Baumgarten has already dealt with this in the Preface to the third edition of the Metaphysics, where he responds to a very similar objection that: "If the principle of ground were universal, the first notes of things would have a ground, and there would be something prior to the first." So just as Kant objects, there would be no first. To this Baumgarten responds: 
The notes of things that are relatively first, or first with respect to human knowledge..., certainly still have a ground, although we do not know this ground in respect to the rest of its predicates in a way that would allow us to separate it sufficiently from the others. And hence there is always something prior to the first in clear and distinct human knowledge, which can only ever be known somewhat obscurely by humans. ... But the absolutely first being as such neither abstracts, nor reflects, and hence, since it knows all things most distinctly from everything else, is never led back to absolutely first notes. (Baumgarten 2013, p. 80)

It is thus only because, as finite rational beings, we can understand some things more easily through other things that these latter are considered to be grounds. But in reality, all things are absolutely coordinated in such a way that in principle anything can be taken as the ground from which all other things are understood. This means not only that everything is a consequence, but also that everything is a ground, which is a principle that Baumgarten accordingly proves in a way that exactly parallels his proof of the PSR (Baumgarten 2013, p. 105).

This means that the more fundamental concept for Baumgarten is that of universal connection, or the nexus between all possible things. The principle of sufficient reason is, as it were, one way in which this universal connection is manifest in the reasoning of finite rational beings. It is possible to find a reason or ground for any given thing precisely because all things are connected so that they mutually imply one another. For the same reason, it is always possible to think of any given thing as the ground for something else. Baumgarten himself points us in this direction by twice stating that if one does not like the main proof, then the PSR can also be derived from the proof of the principle of universal harmony by abstraction, i.e. by attending simply to a part of it (Baumgarten 2013, p. 104). This also means that that the difference between grounds, which are prior in our reasoning, and consequences, which occur later in it, attaches only to finite human reasoning. There is a before and after for us in reasoning only because for us some things are easier to understand than others and so it is through these that we must understand all other things. But the divine intellect, which contains the most adequate representation of the truth, labors under no such restriction.

Ironically, this means that from Baumgarten's point of view, Kant's own claim that the statement "everything is a consequence" is patently absurd, must rest on a failure to distinguish the conditions of human knowledge from the conditions of the things themselves, a distinction Baumgarten believes himself to have properly drawn. 


\section{Conclusion}

I do not presume to have provided any general justification for the PSR or to have vindicated Baumgarten's attempted proof in particular. What I have done is to show that the main objections to Baumgarten's proof voiced by his contemporaries and by the pre-Critical Kant rest largely on misunderstandings of the proof itself and of its place in the wider context of Baumgarten's metaphysical system. In formulating his proof, Baumgarten neither equivocates nor begs the question; his proof cannot be refuted by comparison and it does not support a principle that is self-evidently false. If Baumgarten is nevertheless in error - and there are surely good reasons to think he may be - then this also cannot not be due simply to his having mistakenly identified the first principles of human knowledge with the first principles of beings, since he makes no such identification. It also cannot be due to Baumgarten's having assumed that human knowledge can in any way genuinely approach divine knowledge, since he asserts rather that the two are distinct not only in degree, but also in kind (Baumgarten 2013, §249). ${ }^{10}$ Whatever else one might say, these cannot be the sources of Baumgarten's error.

\section{Bibliography}

All writings by Immanuel Kant are cited by the appropriate abbreviation followed by the volume and page number of Kant's gesammelte Schriften (AA). All translations of Kant's published writings are taken from the Cambridge Edition of the Works of Immanuel Kant. Translations from Kant's Nachlass are my own.

BAUMGARTEN, Alexander (2013), Metaphysics: A Critical Translation with Kant's Elucidations, Selected Notes, and Related Materials, translated and edited with an introduction by Courtney D. Fugate and John Hymers, London: Bloomsbury.

BAUMGARTEN, Alexander (1741), Philosophische Breife von Aletheophilus, Frankfurt and Leipzig.

BAUMEISTER, Friedrich Christian (1747), Elementa Philosophidae Recentoris, Leipzig: Gleditsch.

BAUMEISTER, Friedrich Christian (1754), Institutiones Metaphysicae, Wittenberg: Zimmerman.

CRUSIUS, Christian August (1987), Dissertatio philosophica de usu et limitibus principia rationis determinantis, vulgo sufficientis, in: Die philosophischen

${ }^{10}$ For a fuller discussion of this point, see Baumgarten 2013, p. 22-25. 
Hauptwerke, Teil 1, ed. by Sonia Carbonici and Reinhard Finster, Hildesheim: Olms, 182-327.

KANT, Immanuel (1992), Theoretical Philosophy, 1755-1770, translated and edited by David Walford and Ralf Meerbote, Cambridge: Cambridge University Press.

LONGUENESSE, Béatrice (2005), "Kant's Deconstruction of the Principle of Sufficient Reason", in: Kant on the Human Standpoint, Cambridge: Cambridge University Press, p. 117-142.

MEIER, Georg Friedrich (1755), Betrachtungen über die Schrancken der menschlichen Erkenntnis, Halle: Hemmerde.

REINBECK, Johann Gustav (1740), Betrachtungen über die in der Aubspurgischen Confession enthaltene und damit verknüpfte Gottliche Wahrheiten, Erster Theil, Berlin.

WOLFF, Christian (1747). Vernünffige Gedancken von Gott, der Welt und der Seele des Menschen, auch allen Dingen überhaupt, new enlarged edition, Halle: Rengerischen Buchhandlung.

WOLFF, Christian (2005), Erste Philosophie oder Ontologie: Lateinisch Deutsch translated and edited by Dirk Effertz, Hamburg: Felix Meiner.

\begin{abstract}
This paper defends the Principle of Sufficient Reason, taking Baumgarten as its guide. The primary aim is not to vindicate the principle, but rather to explore the kinds of resources Baumgarten originally thought sufficient to justify the PSR against its early opponents. The paper also considers Baumgarten's possible responses to Kant's pre-Critical objections to the proof of the PSR. The paper finds that Baumgarten possesses reasonable responses to all these objections. While the paper notes that in the absence of a response to Kant's Critical discussion of the PSR (which is omitted here due to limitations of space), this result does not vindicate the principle, it shows how this discussion provides a deeper understanding of what, according to Baumgarten, the PSR really assumes and intends, and prepares the way for a more responsible discussion of Kant's critical objections to Baumgarten's supposed proof.
\end{abstract}

Keywords: Principle of Sufficient Reason, Baumgarten, Kant, pre-Critical, Wolff

\title{
RESUMO
}

Este artigo advoga o Princípio da Razão Suficiente, tomando Baumgarten como seu guia. O objectivo principal não é justificar o princípio, mas antes explorar os tipos de recursos que Baumgarten inicialmente julgou suficientes para justificar o PRS contra os seus primeiros oponentes. $\mathrm{O}$ artigo considera também as possíveis respostas de Baumgarten às objecções pré-críticas de Kant em relação à prova do $\mathrm{PRS}$. $\mathrm{O}$ artigo considera que Baumgarten possui respostas razoáveis a todas estas objecções. Ainda que o artigo note que na ausência de 
uma resposta à discussão crítica de Kant do PRS (que aqui se omite por limitações de espaço), este resultado não vindica o princípio, ele mostra todavia de que modo esta discussão faculta um entendimento mais profundo daquilo que, segundo Baumgarten, o PRS realmente assume e pretende, e prepara o caminho para uma discussão mais informada das objecções críticas de Kant à suposta prova de Baumgarten.

Palavras-chave: Princípio da Razão Suficiente, Baumgarten, Kant, Pré-Crítica, Wolff 